\title{
DIPLOMASI MARITIM INDONESIA DI IORA PADA KASUS ILLEGAL, UNREPORTED, DAN UNREGULATED FISHING
}

\author{
Hino Samuel Jose ${ }^{1}$, Laode Muhamad Fathun ${ }^{2}$ \\ ${ }^{1}$ Program Studi Ilmu Hubungan Internasional Fakultas Ilmu Sosial dan Ilmu \\ Politik Universitas Pembangunan Nasional Veteran Jakarta, \\ abrahamhinosamueljose@upnvj.ac.id \\ ${ }^{2}$ Program Studi Ilmu Hubungan Internasional Fakultas Ilmu Sosial dan Ilmu \\ Politik Universitas Muhammadiyah Yogyakarta
}

\begin{abstract}
Maritime sovereignty is an integral part of the Indonesia's foreign policy, historically in the era of Nusantara, many competitions to conquer maritime territory was even tangible from the era of Majapahit and Sriwijaya kingdom during their ruling. With the notion of Indonesia as the world's maritime axis, Indonesia's diplomacy is defined clearly by the manifestation of efforts either in bilateral, regional, and multilateral. This article discussed on how Indonesia's diplomacy through IORA cooperation is done to overcome the issue of IUU fishing during the presidency of Joko Widodo from 2015 until 2020. Indonesia's IORA Chairmanship from 2015-2017 has rejuvenate Jakarta's maritime diplomacy. Indonesia's diplomacy depicted that Indonesia is beyond than norm-setting but also to the level where Indonesia assert their identity as a sovereign maritime axis amid the challenges and modernization that made non-traditional security as one of the core of contemporary diplomacy.
\end{abstract}

Keywords: IORA, IUUF, Indian Ocean, Maritime Security, Diplomacy

\section{PENDAHULUAN}

Kedaulatan suatu negara tidak hanya berbicara pada satu konteks tetapi juga meliputi berbagai hal yang berkaitan satu sama lain (Sheehan, 2006). Negara mempertahankan kedaulatannya baik di darat, laut, dan udara dari ancaman melalui tindakan sekuritisasi. Tindakan sekuritisasi tentunya dilakukan baik melalui cara tradisional yang lebih bersifat militeristik ataupun menggunakan diplomasi serta perjanjian internasional. Isu keamanan maritim salah satunya, merupakan aspek yang menjadi kunci dari kedaulatan serta keamanan suatu negara - dikarenakan laut menyimpan sumber daya milik negara tersebut ataupun sebagai wilayah strategis/perairan di bawah 
kedaulatan suatu negara. Adanya ketidakamanan maritim (maritime insecurity) tentunya tidak hanya berpengaruh bagi status quo domestik namun juga negara lain. Biersteker dan Weber (1996) menulis bahwa kedaulatan juga mengatur tatanan hubungan antar negara. Ancaman terhadap perairan suatu negara baik yang datang dari aktor negara maupun non-negara tentunya harus dapat mengancam kepentingan komersial yang dampaknya akan berbanding lurus dengan situasi politik domestik maupun hubungan bilateral suatu negara. Contohnya adalah masalah Indonesia dengan kapal asing pencuri ikan Vietnam pada Oktober 2020, pada saat itu perbatasan Zona Ekonomi Eksklusif (ZEE) yang tumpang-tindih membuat Indonesia harus mempercepat negosiasi perbatasan demi keamanan para nelayan Indonesia dan untuk kedaulatan wilayah NKRI (Jelita, 2020).

Keamanan maritim yang diperjuangkan baik secara militer maupun diplomasi menurut Buzan et. al. (1998) adalah suatu konteks dari objek pemikiran non-tradisional yang telah diperluas. Hal ini membuat aktor negara sebagai pembuat kebijakan harus meningkatkan kerjasama maritim yang dibutuhkan sebagai langkah strategis dengan negara lain (Keliat, 2009). Pada permasalahan penangkapan ikan yang ilegal dan tidak sesuai hukum internasional (IUU Fishing atau yang disingkat IUUF) - dampak yang dihasilkan bersifat multidimensional dan mempengaruhi tingkat kompetisi pasar perikanan itu sendiri. Narasi ini diperkuat dengan kesimpulan dari FAO dimana ketidakamanan pangan (food insecurity) menjadi salah satu dampak terbesar apabila IUUF tidak diatasi (FAO, 2016).

Menurut Kementerian KKP RI luas wilayah perairan Indonesia adalah total 7,8 juta $\mathrm{km} 2$ dan 2,55 juta $\mathrm{km} 2$ diantaranya adalah luas dari ZEE Indonesia, dengan data demikian maka potensi laut Indonesia menjadi suatu dorongan untuk dilindungi karena perikanan merupakan salah satu sektor yang berkontribusi terhadap nilai ekspor sebesar 73,6 miliar rupiah (Pratama, 2020). Setelah mengetahui akan potensi ekonomi maritim Indonesia, maka dapat disimpulkan bahwa Indonesia sebagai aktor negara yang rasional tentunya 
harus memprioritaskan bagaimana agar perlindungan potensi laut dapat dimanfaatkan secara sah dan menguntungkan bagi Indonesia, dan keamanan maritim merupakan jawaban untuk Indonesia dorong. Dengan bentuk negara Indonesia sebagai suatu negara kepulauan, maka dalam usaha mempertahankan kesinambungan keamanan maritim Indonesia, maksimalisasi peningkatan diplomasi maupun pertahanan tidak hanya secara politis namun juga secara natural (Fathun, 2019). Dengan kondisi demikian, maka setiap langkah maksimalisasi harus dilakukan dengan mempertimbangkan juga aspek internal maupun eksternal dari rezim yang telah dibentuk berdasarkan prakondisi baik secara historis maupun strategis yang ada sebelumnya.

Ketika meninjau permasalahan maritim, maka akan muncul beberapa proposisi yang umumnya secara normatif akan dibahas sebagai suatu tekanan (pressing matters). Pertama, keamanan maritim dalam segi ekonomi tidak hanya dapat membantu keberlanjutan pembangunan, namun juga sebagai salah satu nilai kerjasama strategis yang menjaga keberlangsungan interdependensi yang signifikan sebagai salah satu komoditi utama di pasar konsumsi (Ridho \& Sudirman, 2020). Oleh karena itu, nilai strategis ini akan menjadi salah satu variabel untuk menjaga resiprokalitas dari hubungan yang dilakukan. Kedua, setiap kebijakan akan memiliki tekanan dikarenakan keamanan maritim adalah sesuatu yang unik pada umumnya, sehingga tindakan sekuritisasi tidak hanya membutuhkan langkah militer maupun hukum yang strategis, namun dapat menjaga agar setiap langkah tidak akan menimbulkan ketidakstabilan antar aktor baik secara bilateral maupun kawasan (Damayanti, 2017). Dan ketiga, 'budaya' dari preservasi keamanan dan gagasan maritim tersebut harus menciptakan keharmonisan antara para pemangku kepentingan yang dalam hal ini tidak hanya pemerintah namun juga aktor komunal seperti contoh yaitu para nelayan, LSM lingkungan, dan konsumen dari produk kelautan tersebut (Fathun, 2019). Adapun berdasarkan narasi tersebut, maka dalam permasalahan maritim seperti IUU fishing membutuhkan kerjasama dengan pihak eksternal baik untuk membangun kesiapan dan kapasitas kebijakan 
aktual, pengarusutamaan kolaborasi teknis maupun pengetahuan, dan strategi yang mengedepankan perdamaian dan keamanan.

\section{Landasan Konseptual Diplomasi Maritim}

Keamanan maritim dalam artikel ini dibahas dalam mazhab nontradisional dikarenakan IUU fishing dilakukan oleh aktor non-negara pada umumnya. Hoyt (2003) telah menarik garis perbedaan antara kontekstualisasi keamanan tradisional dan keamanan non-tradisional. Dan dengan demikian dikarenakan IUU fishing dalam hal ini adalah masalah yang bersifat transnasional, maka akan memenuhi bentangan keamanan non-tradisional yang dibahas oleh Hoyt. Dengan asumsi demikian, maka keamanan maritim tidak hanya sebatas mengatur peran dan strategi dari tentara AL suatu negara (Juliawati, 2018) tetapi juga menjadi dorongan untuk adanya perluasan hingga ke permasalahan non-tradisional. Penelitian-penelitian yang ada mengenai keamanan maritim umumnya berangkat pada argumen dimana resolusi MU PBB yaitu informal consultative process (ICP) merupakan benchmark dari usaha multilateral untuk penanganan kejahatan dan ancaman terhadap keamanan maritim yang bersifat non-tradisional, namun ICP tidak secara eksplisit mengedepankan isu penangkapan ikan ilegal/ IUU fishing sebagai bagian dari norma yang ditetapkan.

Hingga ketika PBB melalui resolusi di tahun 2002 secara eksplisit mengeluarkan resolusi 57/142 pada tahun 2002 dan 70/235 pada tahun 2015 yang menjadi bagian dari "Oceans and The Law of the Sea" menggabungkan IUU fishing sebagai salah satu ancamanan yang perlu diatasi melalui bilateral, regional, dan multilateral. Ketika merefleksikan hal tersebut, maka gagasan akan penanganan permasalahan IUU fishing mendorong cara yang lebih kolaboratif ketimbang cara tradisional yang koersif, hal ini dilakukan melalui postur atraksi dan nilai-nilai prinsipal ketimbang alat-alat perang (Mière, 2014). Secara domestik, konseptualisasi dari diplomasi maritim Indonesia secara pilar tergabung dalam gagasan diplomasi $4+1$ dan bersinggungan antara pilar 
diplomasi kedaulatan, diplomasi ekonomi, dan kontribusi serta kepemimpinan Indonesia di kawasan dan dunia (Hasugian, 2019)

Artikel ini membahas bagaimana diplomasi Indonesia dilakukan dalam isu keamanan maritim pada konteks kerjasama IORA di lanskap Indo-Pasifik. Penelitian ini menggunakan analisis kualitatif dari literatur dan data pendukung yang ada baik secara studi kasus maupun dari rezim keamanan maritim di IORA itu sendiri. Penelitian ini menggunakan document-based dan internet-based research dalam perolehan bahan studi pustaka dan kajian kontemporernya itu sendiri.

\section{PEMBAHASAN}

\section{Rezim Keamanan Maritim Ditinjau dari Perspektif Asia Tenggara}

Keamanan maritim di kawasan Indo Pasifik adalah suatu tindakan sekuritisasi yang didorong oleh definisi Indo Pasifik sebagai suatu "konektivitas ekonomi dan keamanan antara Pasifik Barat dengan Samudera Hindia (Brewster, 2016). Adapun norma kerjasama kawasan Indo Pasifik yang dimana ASEAN menjadi aktor sentralnya mengedepankan norma rule-based order berdasarkan pada hukum internasional yang berlaku yaitu United Nations Convention on the Law of the Sea (UNCLOS). Adapun suatu tatanan rule-based order ini selain menjadi landasan kerjasama dan diplomasi negara-negara Asia Pasifik juga menjadi suatu isu geopolitik yang dimana menurut Singh (2017) ada 3 hambatan struktural yaitu: (1) legitimasi serta advokasi dari para aktor pendorong tatanan rule-based order, (2) permasalahan mengenai keadilan dari para pemangku kepentingan secara proporsional; dan (3) permasalahan mengenai penegakan dan kepatuhan para aktor dalam operasionalisasi kerjasama Indo-Pasifik yang rule-based (Singh, 2017). Dari ketiga masalah tersebut, maka suatu rezim keamanan di Indo-Pasifik, yang dimana dalam konteks ini adalah keamanan maritim harus dibentuk sebagai bagian dari usaha politis untuk mempertahankan gagasan tersebut. 
Terorisme di laut menurut adalah suatu ancaman keamanan maritim yang bermuatan politis ketimbang profit-oriented seperti apa yang dilakukan para jaringan kejahatan transnasional di laut (Shie, 2004). Status quo yang semakin kompleks membuat ASEAN harus memperluas kerjasama intra kawasan-nya hingga keluar dengan mitra strategisnya untuk mengedepankan sekuritisasi dan kepentingan politik maritim semua negara kawasan tersebut. ASEAN dalam hal ini memiliki suatu PR untuk menegakkan hukum dalam sekuritisasi ancaman keamanan maritim melalui diplomasi. Namun, karena definisi yang belum jelas, ASEAN masih harus menggunakan pedoman yang disusun oleh Maritime Cooperation Working Group of the Council for Security and Cooperation in the Asia Pacific (CSCAP). Adapun definisi tersebut belumlah cukup kuat untuk dijadikan norma dasar dalam pengaturan masing-masing negara untuk menangani terorisme di laut (Wee, 2008). ASEAN dan kerangka kerjasama eksternalnya melalui ARF harus memiliki norma pengaturan dasar untuk mengarahkan pandangan yang sama dan mendorong negara untuk memanifestasikan komitmennya. Adapun Bateman (2005) mengatakan bahwa kurangnya pengaturan internasional yang juga disebabkan oleh kurangnya kohesivitas aktor intra kawasan juga menjadi faktor proliferasi kasus terorisme di laut (Bateman, 2005). ARF dalam hal ini hadir dengan mekanisme kerjanya dengan menjunjung tinggi ASEAN Way sebagai media untuk diplomasi maritim para aktor.

ARF didirikan sejak tahun 1994 dan menjadi salah satu manifestasi kepentingan ASEAN dalam bidang politik dan keamanan walaupun pada mulanya ASEAN didirikan untuk kepentingan ekonomi dan sosial budaya (Severino, 2006). Paragraf selanjutnya dibawah ini akan mengelaborasikan lebih lanjut bagaimana ARF melalui mekanisme kerjanya menyelesaikan permasalahan keamanan maritim melalui diplomasi dengan mitra eksternal ASEAN yang tetap berdasar pada tiga prinsip ASEAN yaitu consensus, confidence building, dan non-intervention. Tentunya pelaksanaan diplomasi maritim di ASEAN merujuk pada cetak biru ASEAN yang terbaru yaitu ASEAN 
Political Security Blueprint 2016-2025 yang fokus pada peningkatan kerjasama kawasan dalam isu keamanan non-tradisional, dan juga berbagai isu transnasional (Fajriah \& Latifah, 2018). ARF sendiri melalui ARF Vision Statement menetapkan 5 inti utama yaitu: (1) pembangunan perdamaian kawasan, persahabatan, dan kesejahteraan; (2) guiding principle dalam pendekatan kawasan terhadap isu perdamaian dan keamanan di ASEAN; (3) peningkatan dan penguatan kerjasama ARF melalui diplomasi preventif; membangun kemitraan untuk keamanan yang komprehensif; dan implementasi yang ditinjau secara berkala (ARF, 2009). Visi yang dituangkan pada dokumen ini menunjukan bahwa ASEAN senantiasa mengedepankan sentralitasnya, yang dimana ini merupakan suatu target pencapaian untuk tetap memajukan institusionalisasi kawasan yang nantinya dapat mengelaborasikan solusi yang tetap sejalan dengan dinamika arsitektur keamanan kawasan.

Visi tadi kemudian dikembangkan ke dalam suatu rencana aksi konkret yang dikenal dengan nama Hanoi Plan of Action to Implement ARF Vision Statement yang menjadi landasan untuk ARF di pertemuan Inter-sessional Meeting on Maritime Security. Rencana aksi yang disusun di Hanoi pada tahun 2010 yang dinegosiasikan pada saat ARF Senior Official Meeting menetapkan solusi untuk implementasi visi ARF. Adapun dari 6 area kerjasama yang dicakup dalam rencana strategis ini, yang paling relevan adalah area kerjasama keamanan maritim. ARF Intersessional Meeting on Maritime Security (ARF ISM on MS). Rencana aksi Hanoi menargetkan pada tahun 2020, ARF sudah mengembangkan solusi regional konkrit yang efektif. Usaha-usaha sendiri diwujudkan melalui beberapa langkah strategis seperti: (1) konsultasi untuk kerangka kerja isu keamanan maritim; (2) kerjasama intensif dan dekat untuk membahas keamanan navigasi dan standar pengamanan para pelaut serta kapal yang beroperasi sesuai dengan standar regional; (3) promosi keamanan regional melalui pembangunan kapasitas dan pelatihan para pejabat untuk berlatih bersama dalam menangani isu yang terkait dengan keamanan maritim; (4) mengembangkan jejaring antara ARF dengan IMO, IOR-ARC, ReCAAP, dan 
platform kerjasama maritim lainnya; (5) pengembangan teknologi dan kapasitas penegakan hukum; dan (6) melibatkan pemikir (think-tank) dari level nasional maupun regional untuk mendukung ISM on MS dalam pembuatan kebijakan yang transparan dalam isu keamanan maritim.

Implementasi kedua kerangka kerja haruslah meninjau apa saja kelemahan dan ruang untuk diperbaiki. Dalam hal ini, luasnya wilayah laut yang dicakup oleh ARF di Asia Pasifik membuat kapitalisasi sumber daya maritim dari setiap aktor negara harus mampu bersinergi dan memenuhi standar operasi. ARF dibuat sebagai suatu media kerjasama transregional yang berfungsi untuk mendirikan pilar sentral ASEAN dalam menangani evolusi tantangan keamanan kawasan (ARF, 2009). Oleh karena itu, perlu diketahui bahwa kemitraan ASEAN dengan negara-negara sahabat di luar ASEAN merupakan suatu usaha untuk menciptakan pola hubungan yang konstruktif berdasarkan berbagai pola yang terprediksi di Asia Pasifik di tengah tantangan yang ada (Leonard, 2019).

ARF sendiri melalui mekanisme ISM on MS beberapa kali membahas beberapa kasus yang terjadi di Selat Malaka dan Laut Filipina. Pada kasus Filipina, yang difokuskan adalah penanganan kelompok Abu Sayyaf yang merupakan teroris. Kelompok ini dianggap sangat berbahaya dan sangat bermuatan politis disamping keperluan ekonomi dikarenakan kelompok ini berusaha untuk mencari dana operasi ketimbang operasi pembajakan untuk pengaruh semata. Tiga kasus penyanderaan yang berujung pada tewasnya WN Kanada dan bebasnya 2 WN Malaysia dan Indonesia membuat perairan ini masih rawan walaupun kecaman internasional sudah dilemparkan ke Abu Sayyaf (Djelantik, 2016).

Kemudian pada Selat Malaka, sebagai wilayah strategis tentunya secara geopolitik merupakan jalur perairan yang menghubungkan wilayah Samudera Hindia dengan Laut Cina Selatan, yang dimana ini merupakan jalur perdagangan Asia Tenggara dari Pasifik menuju Samudera Hindia hingga ke 
Eropa. Jalur perdagangan ke negara Asia Selatan seperti India dapat diperpendek jalur tempuhnya melalui selat Malaka. Namun, ancaman pembajakan masih ada ketika pada tahun 2014 ada 4 pembajak dari Aceh yang menahan kapal asal Thailand 213 MOO8 Tamban Hin Muong Suvarnabhumi ROI (Fathun, 2019). Tindakan para pembajak tersebut merupakan motif ekonomi, hal ini membuat bahwa lokalisasi pembangunan berkelanjutan di wilayah perbatasan perlu ditingkatkan. Dan tentunya ini dapat menjadi salah satu konten negosiasi ARF dalam penetapan solusi di ISM on MS berikutnya pada tahun 2021. Menurut IMO, laut selat Malaka menghadapi kasus pembajakan serius dengan angka 108 kasus perompakan pada tahun 2015 dan $72 \%$ lalu lintas perdagangan internasional terancam (Djelantik, 2016).

Umumnya, karena belum ada konsensus atau landmark yang bisa menjadi acuan dalam keamanan maritim, diplomasi yang dilakukan semuanya memiliki kesamaan ciri khas yaitu keamanan maritim merupakan konstruksi sosial yang dianut oleh negara dalam menindak kebijakan sekuritisasi maritim baik secara militer maupun nonmiliter yang transnasional dan tidak terikat pada batas-batas wilayah negara (Fathun, 2019). Usaha seperti cuci uang dan sebagainya diperketat dan dalam hal ini efisiensi kerjasama lembaga antar pemerintah harus lebih cepat untuk melakukan tindakan remedial atau diplomasi preventif yang proaktif. Kasus ini sendiri ditangani melalui solusi grand strategy yang merupakan arti dari penegakan hukum, stabilitas, dan strategi pemerintah untuk melakukan kontrol (Permono, 2019). Kontrol ini dilakukan untuk mencegah adanya pencapaian secara ideologis maupun politis dalam konteks keamanan maritim. ARF melalui ISM on MS menetapkan kebijakan sekuritisasi yang aktual dan mampu mendorong paradigma diplomasi kolaboratif.

\section{IUU Fishing dan Tinjauan Kontemporer Keamanan Maritim Indonesia}

Seperti yang telah dibahas sebelumnya, dengan kondisi dimana Indonesia memiliki tekanan baik dari dalam maupun dari luar untuk menjaga interdependensi dan melakukan preservasi pada kedaulatan dan keamanan 
maritim, maka Indonesia harus memulai langkah strategis dan solutif yang dapat menjaga potensi laut Indonesia dari tindakan ilegal. Salah satu permasalahan yang paling sering terjadi adalah penangkapan ikan ilegal yang secara internasional dikenal sebagai illegal, unregulated, and unreported fishing (IUU Fishing). IUU Fishing sendiri adalah suatu istilah yang dipergunakan secara luas dan memiliki cakupan yang multidimensional mengenai perikanan (FAO, n.d).

IUU Fishing dinilai bukanlah suatu masalah yang unik bagi Indonesia jika melihat pada status quo (Taufika, 2020), namun konsekuensi dari IUU Fishing sendiri apabila tidak ditangani secara berkelanjutan akan merugikan Indonesia sebab kebanyakan dari sektor perikanan dan kelautan Indonesia bersifat informal dan dipegang oleh para smallholders. Untuk mendalaminya OECD (2004) mengelaborasikan 3 konsekuensi utama dari IUU fishing yang apabila terjadi pada negara ekonomi berkembang akan merugikan: (1) berkurangnya sumber daya perikanan yang dapat dikelola secara efektif; (2) berkurangnya kesempatan untuk ekonomi para nelayan; dan (3) munculnya ketidakamanan pangan (food insecurity). Dan konsekuensi ini tentunya tidak dapat diatasi dengan strategi satu dimensi (OECD, 2004) dan memerlukan whole-stakeholder approach atau pendekatan pemangku kepentingan secara menyeluruh dan tidak menutup kemungkinan adanya integrasi usaha dari kerjasama level internasional.

Pada UUD 1945 pasal 4 ayat 1 menjadi landasan dasar akan kepentingan maritim Indonesia. Ketetapan agenda Indonesia akan konteks maritim terlihat kembali saat pada tahun 2017 Presiden Joko Widodo menetapkan Peraturan Presiden RI (Perpres) No. 16 Tahun 2017 tentang Kebijakan Kelautan Indonesia yang menjadi dasar dari sekuritisasi Indonesia sebagai poros maritim dunia. Adapun langkah sekuritisasi tersebut merupakan wujud kesadaran pemerintah Indonesia dalam melindungi potensi sumber daya perikanan Indonesia sebesar 9,9 juta ton per tahun dan untuk mendorong pemanfaatan sumber daya ikan yang berkelanjutan dan mengurangi overfishing. Perikanan memang dipandang 
sebagai sumber daya terbarukan, namun artikulasi kebijakan pemerintah sesuai dengan yang dimandatkan pada Peraturan Menteri KKP No. 31 tahun 2004 serta UU No. 45 tahun 2009 harus memastikan agar potensi perikanan Indonesia dimanfaatkan dengan menjaga laju ekstraksi agar proporsional dengan laju pemulihannya (Suman, Irianto, Satria, \& Amri, 2016). Dari hal tersebut maka IUU fishing secara signifikan akan kontraproduktif dengan peraturan dan mandat yang telah ditetapkan sebagai norma kebijakan maritim Indonesia.

Diluar konteks hukum dan juga kebijakan, salah satu permasalahan utama adalah letak geografis dari Indonesia itu sendiri. Kondisi geografis Indonesia yang cukup strategis menghubungkan dua samudra besar dan dua benua menjadi alarm bagi Indonesia untuk membuka jalur kerjasama dan diplomasi dengan negara tetangganya dan bahkan pengarusutamaan prinsipprinsip serta norma dalam level intra dan antar kawasan. Usaha diplomasi maritim, menjadi salah satu elemen yang memiliki intensitas penting (Anwar, 2016) dikarenakan aktor pelaku yang terlibat dalam kasus IUU Fishing umumnya adalah WNA sehingga membutuhkan negosiasi dan pembahasan mengenai hal strategis maupun teknis seperti yurisdiksi hukum, perjanjian keamanan perbatasan laut, dan sebagainya.

Dalam kajian keamanan maritim kontemporer, umumnya permasalahan yang dihadapi adalah konflik yang tidak bersifat terbuka, namun menurut penulis ini juga didampingi dengan adanya perdamaian negatif yang tercipta di suatu arsitektur kawasan. Tentunya identitas kebijakan luar negeri yang terkait dengan isu maritim suatu negara akan tegak lurus dengan kondisi geopolitik, serta bagaimana jalur komunikasi dan penyelesaian isu dilakukan baik antara aktor negara maupun aktor non-negara. Tentunya dalam kasus diplomasi maritim Indonesia di IORA pula, apa yang menjadi kepentingan Indonesia dibawa dengan posisi yang mempertimbangkan distribusi power di suatu wilayah maritim. Hal ini karena isu kedaulatan menjadi hal yang tidak dapat ditawar, sambil para negara yang bekerjasama menyusun norma maritim 
mereka untuk memanfaatkan keunggulan komparatif masing-masing dalam isu maritim (Waluyo, 2020).

Kasus yang terjadi selama rentan waktu 2019-2020 cenderung naik turun, ketika Menteri Susi Pudjiastuti menjabat sebagai Menteri KKP, dari Januari 2019 hingga April 2019 terjadi penangkapan terhadap 38 kapal asing yang melakukan tindakan IUU Fishing dimana 15 kapal berasal dari Vietnam, 13 kapal dari Malaysia, dan 10 kapal merupakan kapal asal Indonesia (KKP RI, 2019). Yang dimana penangkapan tersebut dilakukan pada wilayah penangkapan perikanan (WPP) sektor $711,712,713$, dan 716 yang merupakan hasil kinerja yang positif pada kuartal pertama tahun 2019. Tindakan sekuritisasi seperti penangkapan dan penghancuran kapal asing merupakan salah satu tindakan khas dari pemerintah dalam penanganan isu ini. Tindakan yang dilakukan pemerintah pun beragam, mulai dari tindakan pencegahan, penanganan agar tidak dimanipulasi oleh para kapal pencuri ikan, dan kemudian menegakan hukum dengan mengatasi kerumitan yang ada dalam konteks kasus IUU Fishing yang berfokus juga pada penangan kejahatan transnasional. Bahkan, dengan salah satu WPP di Indonesia yaitu WPP 715 yang memiliki nilai potensi ekonomi sebesar 3,6 miliar/ tahun maka pengawasan terhadap wilayah-wilayah vital ini perlu diperketat (Susanti, Fahrudin, \& Kusumastanto, 2020).

\section{Diplomasi Indonesia Melalui IORA pada Kasus IUU Fishing}

IORA sadar betul bahwa kawasan samudera hindia selain daripada keuntungan geopolitik, juga menyimpan sumber daya laut yang melimpah. Sumber daya laut yang kaya akan ikan dan keanekaragaman maritim lainnya menjadi suatu identitas kerjasama intrakawasan negara-negara anggota IORA (IORA, n.d). IORA pada tahun 2018 - 2020 menetapkan kerangka kerja yang menghasilkan rencana aksi untuk isu manajemen perikanan berkelanjutan (sustainable fisheries management) demi melindungi 28,5 juta orang yang dipekerjakan pada sektor perikanan. $47 \%$ dari 441 titik cadangan sumber daya perikanan telah dieksploitasi dan $18 \%$ diantaranya dieksploitasi secara tidak 
bertanggung jawab (IORA, n.d). Forum kerjasama IORA yang telah dibentuk sejak tahun 1997 memiliki tujuan utama untuk meningkatkan kesejahteraan dan kerjasama ekonomi maritim, yang dimana IORA menjadi asosiasi kerjasama dengan luas wilayah maritim terbesar ke-3 dengan 21 negara anggota dan 7 mitra dialog (Lisbet, 2016). Kerjasama maritim yang dilakukan IORA memiliki beberapa mekanisme kerja utama yang ditetapkan oleh Jakarta Concord's Action Plan (2017-2021) yang dijelaskan pada paragraf dibawah ini.

Ada beberapa kelompok kerja di IORA yaitu Kepala Misi Kerja (Working Group on Heads of Mission/WGHM); Perdagangan dan Investasi (Working Group on Trade and Investment/WGTI); Forum Bisnis IORA (IORA Business Forum/IORBF); dan Akademisi. Pertama adalah WGHM atau Working Group on Heads of Mission adalah kelompok kerja tertinggi yang terdiri dari kepala perwakilan misi diplomatik negara-negara IORA yang berbasiskan di Pretoria, Afrika Selatan. Adapun WGHM bertemu untuk membahas program kerja yang dipresentasikan oleh Chair dan dewan Menteri (Council of Ministers) (IORA, n.d). WGHM bertindak sebagai aktor yang mengikuti dan mengarahkan perkembangan isu-isu yang menjadi fokus dan membahas arahan strategis berikutnya. Kedua adalah WGTI atau Working Group on Trade and Investment adalah organ utama yang bertugas untuk membahas kerjasama dagang maritim dan investasi di IORA semenjak 1999. WGTI bekerjasama untuk membahas liberalisasi perdagangan, mengentaskan hambatan dari barang, jasa, dan investasi serta pembangunan teknologi yang dimiliki oleh negara-negara anggota IORA. WGTI juga berfungsi untuk meningkatkan regional supply chain dan memfasilitasi dialog pemerintahan dalam penguatan isu-isu seperti UMKM, partisipasi akademik, dan lainnya (IORA, n.d). WGTI pada tahun 2019 menetapkan beberapa rekomendasi kebijakan yaitu: (1) pengembangan hubungan $\mathrm{P} 2 \mathrm{P}$ (people-to-people) dan dialog B2G (business-to-government) dalam menciptakan mekanisme information sharing antar pemerintah untuk mengentaskan permasalahan dagang dan investasi; (2) fasilitasi inovasi dan pertumbuhan ekonomi melalui kerjasama yang menarik investor; 
mengembangkan strategi IORA Maritime Industry Strategy untuk merealisasikan potensi ekonomi maritim yang besar; dan (4) memajukan agenda kesetaraan gender dalam penguatan ekonomi melalui 7 prinsip kunci IORA serta menciptakan ekosistem kebijakan yang memajukan peran perempuan dan reformasi kebijakan lain berdasarkan rekomendasi UN WOMEN (IORA, 2019).

Ketiga adalah forum bisnis IORA atau IORBF (IORA Business Forum) merupakan media untuk para pelaku bisnis di negara-negara IORA untuk berinteraksi. Para perwakilan bisnis ini juga membahas berbagai upaya yang bisa dilakukan untuk merekomendasikan [pemerintah negara anggota untuk akselerasi perdagangan intrakawasan IORA. Forum ini juga membahas mengenai pentingya peran sektor swasta dalam mempromosikan kerjasama yang berkelanjutan serta implementasi yang berasaskan kerjasama. Adapun kerjasama yang dimaksud adalah kolaborasi dengan Global Trade Review (GTR) untuk membahas tantangan dan peluang bisnis di IORA (IORA, n.d). IORBF juga mengadakan acara jejaring bisnis, dan juga berbagai acara seperti pengembangan kapasitas bisnis dan pelatihan untuk para aktor bisnis dalam mempelajari koordinasi kebijakan dagang dan mengembangkan nilai perdagangan. IORBF pada 2017 mengadopsi deklarasi berjudul "Joint Declaration on the IORA Business Community to Build Partnerships for a Sustainable and Equitable Economic Growth" di Jakarta.

Terakhir adalah akademisi yang memiliki tugas untuk melakukan pengkajian kebijakan dan pengembangan penelitian kemaritiman dalam mendukung riset kebijakan berdasarkan IPTEK. Dalam bidang ini, kelompok kerja ini fokus pada pengembangan pengetahuan melalui publikasi di dua jurnal utama yang dimiliki oleh IORA yang berisi penelitian yang relevan serta membahas berbagai isu tematik dan spesifik. Diplomasi maritim Indonesia tentu tidak terlepas dari kepentingan politik Indonesia, oleh karena itu Pemerintah RI (Pemri) selalu menegaskan bahwa kepentingan Indonesia sebagai penghubung kawasan Asia Timur dan Samudera Hindia harus dijunjung tinggi. Visi Global Maritime Fulcrum (GMF) yang ditekan oleh Presiden Joko Widodo juga 
merupakan kekuatan Indonesia juga sebagai negara non-blok (Akbar, Subagyo, \& Oktaviani, 2020) yang menjaga keamanan maritim sambil menggandeng teman baru dan menjaga relevansi diplomasi middle power dengan status quo.

Kawasan Samudera Hindia adalah kawasan yang paling sulit dimengerti. Adapun alasannya adalah dikarenakan kawasan ini terhubung dan bersinggungan dengan Arab, Timur Tengah, Afrika, Sub-Sahara, dan Asia Selatan (Gupta, 2010). Oleh karena itu sangatlah besar potensi yang perlu dimanfaatkan ditengah proyeksi kekuatan geopolitik yang bersaing di kawasan samudera Hindia. Indonesia dibawah pemerintahan Joko Widodo betul-betul mengedepankan dialog kerjasama maritim seperti yang dibahas sebelumnya. Perubahan paradigma kebijakan Indonesia dalam diplomasi maritim membuat Indonesia ingin memposisikan polugri maritimnya sebagai negara yang hidup dari laut (sea-based) ketimbang hidup dari sumber daya di darat (land-based) (Rezasyah, 2017). Presiden Jokowi dalam beberapa kesempatan terus mengedepankan bahwa laut adalah ujung tombak kedaulatan dan menyimpan ekonomi yang memakmurkan bangsa Indonesia. Jadi kita bisa lihat bahwa visi Indonesia untuk menjadi poros maritim menjadi konten utama dalam diplomasi maritim di IORA. Ancaman ketidakamanan maritim seperti kasus IUUF tentu mendorong posisi Indonesia dalam menciptakan visi maritim dunia yang diadopsi melalui Perpres No. 16 tahun 2017.

Indonesia menjadi ketua (chairman) IORA pada tahun 2015, Indonesia selama masa kekuasaannya di IORA membawa agenda untuk membawa agenda maritim nasional dalam melakukan reorientasi pandangan maritim di Samudera Hindia (Putri, 2018). IUUF tidak ditangani sebaik jaman sekarang sebelum masa pemerintahan Presiden Jokowi, perlu diketahui bahwa kejahatan transnasional telah ter-proliferasi dengan cepat pada saat itu oleh karena kurang kuatnya kebijakan negara dalam aktualisasi gagasan maritim Indonesia (Septaria, 2016). Total $301 \mathrm{kapal}$ asing yang ditangkap pada tahun 2018 saat sedang melakukan IUUF tidak hanya satu-satunya ancaman, namun IUUF juga sering dilakukan oleh nelayan domestik Indonesia yang jumlahnya 138 pakal 
yang tertangkap oleh KKP (Lestari, Putra, \& Larasuci, 2019). Oleh karena itu, Indonesia melalui keketuaannya yang bertemakan "Strengthening Maritime Cooperation in a Peaceful and Stable Indian Ocean" pada tahun 2015-2017 menghasilkan beberapa keputusan: (1) Pertama, IORA membentuk concord sebagai hasil konkrit setelah IORA bekerja selama 20 tahun dan mencoba berbagai usaha restart oleh chair sebelumnya; (2) penguatan regionalisme melalui KTT IORA yang memajukan isu lintas sektoral dan institution-building; dan melakukan kegiatan teknis konkrit yang melibatkan pemangku kepentingan dari kementerian maupun lembaga (Kemlu RI, 2019).

Pasca Indonesia selesai menjalankan keketuaan IORA pada tahun 2017, Indonesia tentunya memerlukan penguatan kerjasama teknis apalagi dalam pengentasan IUUF. Dalam mengukur keberhasilan solusi mengatasi IUUF, Indonesia melalui IORA pasca keketuaannya dapat mengintegrasikan norma yang dibentuk ke kerangka kerjasama ASEAN. Untuk membuktikannya, ASEAN memiliki berbagai kemitraan antar kawasan seperti melalui mekanisme ARF yang juga membahas agenda keamanan maritim. Sehingga dalam hal ini IORA dan ASEAN dapat belajar dari IORA, dan penting untuk regionalisme ASEAN dan memperhatikan kawasan Samudera Hindia yang secara geopolitik dan geografis bersinggungan dengan ASEAN, terutama pada isu non-tradisional tadi (Bhattacharyya, 2010). Indonesia dapat meneruskan institutional building yang tidak akan hilang dalam mengentaskan IUUF. Beragamnya derajat kepentingan politik, ekonomi, dan militer berbagai negara di IORA juga membuat IORA harus belajar dari ASEAN yang masih dapat mempertahankan ASEAN Way di tengah beragamnya derajat kepentingan tersebut. Chew (2011) menganggap suatu kerjasama maritim sangatlah erat hubungannya dengan konteks lain karena maritim merupakan media komunikasi ide dan pertukaran budaya di masa lampau. Kekuatan dari hubungan inilah juga yang menjadi visi Jokowi untuk mengembangkan diplomasi maritim Indonesia melalui IORA serta penguatan investasi di pelabuhan laut dan infrastruktur perikanan dalam meraih keuntungan absolut dari kerjasama maritim (Connelly, 2015). 
Warga lokal yang hidupnya erat dengan laut menjadi perhatian khusus terutama pada konteks pembangunan nasional. IUUF merampas mata pencaharian para warga lokal yang bergantung di pantai sehingga Indonesia melalui IORA mendorong terus gagasan ZOPFAN atau zona wilayah maritim IORA yang lebih "damai, aman, bebas, dan netral (Rezasyah, 2017). Interaksi semacam inilah yang diharapkan dapat menciptakan identitas IORA yang telah terlokalisasi dengan baik dan menciptakan sense of belonging masyarakat dalam bersama-sama melawan IUUF. Kerjasama regional yang sekarang cenderung memiliki statecraft yang berorientasi pada manusia dan agenda keamanan manusia yang semakin kencang (human security) membuat interaksi identitas ini penting (Naidu, 2016). IUUF yang terus dilawan Indonesia juga memberikan suatu pemahaman bahwa dalam konstelasi pengamanan maritim dan diplomasi yang dilakukan memerlukan rasionalisasi. Rasionalisasi disini adalah baik dalam konteks kebijakan domestik maupun eksternal mempertimbangkan potensi dan kapitalisasi yang ada di level nasional dan kekuatan hukum yang memandatkan hal demikian (Wicaksana, 2017). Indonesia melalui lima pilar yang ditetapkan dalam membangun budaya poros maritim dunia juga mengalami tantangan dari situasi politik regional yang ada. IUUF yang dilaksanakan oleh non-state actor (walaupun banyak juga yang statesponsored seperti apa yang dilakukan Tiongkok di Laut Cina Selatan) membuat Indonesia harus sensitif kepada dimensi kerjasama lainnya yang lekat dengan sifat holistik dari konflik maritim itu sendiri. Faktor kedekatan satu negara dengan negara lain dalam menghindari konflik dan menciptakan balance of power membuat Indonesia harus menggemakan nation understanding (Putri, 2016) - untuk mengelola negosiasi. Dan adanya nation understanding ini bisa dibawa dari IORA dimana para negara sama-sama mengerti betul dampak IUUF dan meresonansikan gagasan tersebut agar menjadi norm-setting di ASEAN yang menjadi aktor vital dan mitra dari IORA.

Internalisasi norma di IORA juga menjadi prioritas Indonesia, adapun norma yang dimaksud adalah bagaimana para negara anggota IORA yang 
kebanyakan adalah negara berkembang dapat membangun jembatan dan mengedepankan kolaborasi yang sesuai. Negara berkembang membutuhkan sumber daya dan kapitalisasi yang efektif sehingga kolaborasi demikian (mirip dengan kontekstualisasi Kerjasama Selatan-Selatan) diperlukan oleh negaranegara tersebut. Institusionalisasi yang ada di IORA harus memajukan prinsip dan langkah dimana para negara juga membawa para kelompok kerja di IORA untuk memperluas cakupan kebijakan. Cakupan kebijakan itu sendiri tidak boleh hanya serta merta diperluas dengan kajian akademik maupun pengembangan kebijakan tetapi juga melalui lokalisasi hukum internasional. Hal ini berkaca dari ASEAN yang mampu bertahan dengan tatanan rule-based order-nya. Karena apabila IORA tidak memiliki suatu tatanan demikian maka IORA akan menjadi kerjasama pasif yang kurang menguntungkan dan tidak ada kepatuhan dari para negara-negara. Diplomasi maritim Indonesia juga harus menciptakan vocabulary yang dapat digunakan oleh para aktor negara di IORA untuk berkomunikasi dan mengimplementasikan kebijakan anti IUUF di negara mereka. Serta intensitas kerjasama juga harus didorong dengan eksplorasi insentif yang menguntungkan.

\section{Refleksi Keketuaan Indonesia di IORA 2015-2017 sebagai Usaha Diplomasi Maritim di Indo-Pasifik}

Keketuaan Indonesia di IORA tentunya telah membawa pengaruh yang cukup signifikan untuk diplomasi maritim Indonesia. Visi maritim dibawah Presiden Jokowi yang merupakan bukti pengembangan dari konsep wawasan nusantara membuat strategisasi maritim harus melibatkan semua aktor dalam pendekatan yang kolaboratif. Pembentukan Badan Keamanan Laut (Bakamla) yang salah satunya bertujuan untuk menentang IUUF dapat kita lihat sebagai salah satu usaha untuk mendorong isu kerjasama maritim non-konvensional dan integrasi deteksi dini bersama para aktor. Indonesia sebelumnya telah menerbitkan UU No. 32 tahun 2014 mengenai kelautan, dan UU ini memberikan lanskap yang baik untuk koordinasi antar lembaga pemerintahan dalam keamanan laut, sehingga kejahatan laut menurun 90\% (Ayuningtyas, 2018). 
Selain daripada itu, Indonesia juga memiliki kepentingan akan pengembangan blue economy pada tahun 2015 telah terbentuk melalui IORA Blue Economy Core Group. Adapun peran kelompok ini adalah untuk proses konsultatif yang digunakan Indonesia untuk meningkatkan pertumbuhan PDB di Samudera Hindia melalui ekonomi laut yang aman dan berkelanjutan, serta untuk mendorong pembangunan kapasitas teknis dari IORA (Ayuningtyas, 2018). Prinsip IORA sebagai suatu organisasi yang berasaskan open regionalism serta pertumbuhan keanggotaan sendiri bahkan masih menghadapi beberapa kritik. Tantangan seperti kurang jelasnya pencapaian objektif dan keseragaman pandangan para negara anggota IORA, dimana negara-negara Small Island Developing States (SIDS) lebih menekankan pada permasalahan perubahan iklim dan lingkungan maritim, sementara Australia, India, dan Afrika Selatan lebih kepada isu keamanan maritim dalam konteks tradisional (Prasetyo, 2016).

Kedepannya, ketidaksinergisan seperti itu tentunya harus diatasi dengan penetapan pandangan yang konsisten, dimana rencana aksi/ strategisasi diharapkan bersifat saling memotong (cross-cutting) agar setiap permasalahan yang bersinggungan memiliki solusi komprehensif yang tepat. Indonesia sendiri sebenarnya masih memiliki banyak PR untuk pengembangan infrastruktur kelautan dalam mendukung penegakan keamanan terhadap masalah IUUF. Indonesia juga harus mendorong agar nantinya penyelesaian masalah dan pelaksanaan solusi konkrit harus menghubungkan konektivitas antar negara dengan memanfaatkan pola dari visi maritim global Indonesia. Pola ini nantinya dapat menjadi suatu modal untuk Indonesia menjalin dari level bilateral terhadap negara-negara lain di IORA. Adanya IORA tentu dapat menjawab urgensi dimana dunia membutuhkan platform kerjasama antar kawasan tunggal untuk menghadapi masalah kontemporer kelautan. Adanya kejahatan seperti IUUF tentu membuat masalah multidimensional akan terjadi ditambah dengan fakta bahwa kawasan IORA saat ini menjadi arena pertarungan geopolitik para major power (Setiyanto, 2017). 


\section{KESIMPULAN}

Diplomasi maritim yang dilakukan pemerintah Indonesia melalui IORA tentunya dalam konteks implikasi manajerial akan menghasilkan beberapa narasi berikut ini: (1) pemerintah sebagai aktor harus mampu menggunakan multitrack diplomacy yang dimana mampu memperbaharui paradigma kebijakan maritim yang sudah usang sejak zaman adanya ICP; (2) masyarakat menjadi aktor terdepan dari orientasi kebijakan yang ada karena IUUF dapat menimbulkan ketidakamanan pangan serta kemiskinan; (3) IORA harus menjadi bridge-builder bersama ASEAN dalam menciptakan Indo-Pasifik yang damai dan aman maritimnya; (4) Indonesia pada era pasca keketuaan IORA 2015-2017 diharapkan melalui ASEAN chairmanship pada tahun 2023 dapat mempertimbangkan isu kerjasama antar kawasan ASEAN - IORA yang lebih konkret melawan IUUF; dan (5) improvisasi kerjasama diperlukan dalam membawa deklarasi politik normatif dari Jakarta Concord ke aksi yang berkelanjutan dalam mencapai SDGs 2030. Tentunya ancaman keamanan maritim kontemporer akan terus berubah seiring dengan jaman, sehingga resiliensi dan ketahanan para aktor dalam solusi yang multisektoral diperlukan. Melalui keketuaan Indonesia di IORA, dapat dipelajari beberapa hal penting sebagai berikut: (1) IORA perlu menghasilkan solusi yang lebih konkrit lagi; (2) ASEAN harus membuka kerjasama antar kawasan dengan IORA; (3) Indonesia harus melibatkan konsultasi dengan para aktor non-negara dalam formulasi kebijakan; (4) pengarusutamaan sentralitas ASEAN yang berdasarkan prinsip rule-based order dalam tatanan rezim maritimnya; dan (5) mengedepankan solusi yang melibatkan pentahelix dan inovasi berkelanjutan. Indonesia tentunya harus memainkan diplomasi preventif dan rasionalisasi akan faktor internal dan eksternal yang mempengaruhi sekuritisasi dan diplomasi maritim yang dilakukan. 


\section{REFERENSI}

Akbar, T.H., Subagyo, A., \& Oktaviani, J. (2020). Realisme Dalam Kepentingan Nasional Indonesia Melalui Forum Konferensi Asia Afrika (KAA) Dan Gerakan Non Blok (GNB). Jurnal Dinamika Global, 5(1), 123-129.

Anwar, S. (2016). MEMBANGUN KEAMANAN MARITIM INDONESIA DALAM ANALISA KEPENTINGAN, ANCAMAN, DAN KEKUATAN LAUT. Jurnal Pertahanan, 6(3), 69-89. doi:http://dx.doi.org/10.33172/jpbh.v6i3.315

ARF. (2009). ASEAN Regional Forum Vision Statement. Phuket: ASEAN Regional Forum.

Ayuningtyas, D. (2018). Kepentingan Indonesia Dalam Indian Ocean Rim Association (IORA) Tahun 2015. eJournal Ilmu Hubungan Internasional, 6(1), 1-14.

Bateman, S. (2005). Future Unknown: The Terrorist Threat to Australian Maritime Security. Canberra: Australian Strategic Policy Institute.

Bhattacharyya, A. (2010). "Understanding security in regionalism framework: ASEAN maritime security in perspective. Maritime Affairs: Journal of the National Maritime Foundation of India, 6(2.).

Brewster, D. (2016). Indo-Pacific Maritime Security: Challenges and Cooperation. Canberra: National Security College.

Connelly, A. L. (2015). Sovereignty and the Sea: President Joko Widodo's Foreign Policy Challenges. Contemporary Southeast Asia, 37(1).

Damayanti, A. (2017). Regional Maritime Cooperation in Maintaining Maritime Security and Stability: A Test Case for ASEAN Unity and Centrality. Journal of ASEAN Studies, 5(2), 119-134. doi: $10.21512 /$ jas.v5i2.1888 
Djelantik, S. (2016). Sekuritisasi dan Kerjasama ASEAN dalam Meningkatkan Keamanan di Perairan Kawasan. Jurnal Studi Global \& Strategis, 10(2), 186-203.

Fajriah, A. N., \& Latifah, E. (2018). Peran ASEAN Dalam Menanggulangi Terorisme di Laut Sebagai Ancaman Terhadap Keamanan Maritim. Beli Ac Pacis: Jurnal Hukum Internasional, 4(1), 21-32.

FAO. (2016). Illegal, unreported, and unregulated fishing. New York: Food and Agriculture Organization.

FAO. (n.d). What is IUU fishing? Dikutip Januari 29, 2020, from Food and Agriculture Organization: http://www.fao.org/iuufishing/background/what-is-iuu-fishing/en/

Fathun, L. M. (2019). ASEAN Contemporary Security: Maritime Diplomacy in Handling of Maritime Security Threats in Malaka Strait. Insignia Journal of International Relations, 6(1), 50-63. doi:https://doi.org/10.20884/1.ins.2019.6.1.1414

Fathun, L. M. (2019). ASEAN Contemporary Security: Maritime Diplomacy in Handling of Maritime Security Threats in Malaka Strait. Insignia Journal of International Relations, 50-63.

Gupta, M. (2010). Researching the Indian Ocean Region. In Indian Ocean Region. The Political Economy of the Asia Pacific. New York: Springer.

Hasugian, M. R. (2019, Oktober 29). Menlu Retno Sebut 4+1 Prioritas Politik Luar Negeri RI 2019-2024. Dikutip Januari 29, 2021, from Tempo.Co: https://dunia.tempo.co/read/1265955/menlu-retnosebut-41-prioritas-politik-luar-negeri-ri-2019-2024/full\&view=ok

IORA. (2019). Modernising Trade in the Indian Ocean Rim Conference. Durban: Indian Ocean Rim Association. Dikutip from 
https: / /www.iora.int/media/24133/report-modernising-tradeconference-web-min.pdf

IORA. (n.d). Fisheries Management. Dikutip April 29, 2021, from Indian Ocean Rim Association: https://www.iora.int/en/priorities-focusareas/fisheries-management

IORA. (n.d). Indian Ocean Rim Business Forum (IORBF). Dikutip April 29, 2021, from Indian Ocean Rim Association: https://www.iora.int/en/structuresmechanisms/mechanisms/indian-ocean-rim-business-forum-iorbf

IORA. (n.d). IORA Workshop on Regional strategy to address issues of sustainable management and development of fisheries resources in the Indian Ocean rim region. Dikutip April 29, 2021, from United Nations Ocean Conference: https: / / oceanconference.un.org/commitments/?id=18226

IORA. (n.d). Working Group on Heads of Mission (WGHM). Dikutip April 29, 2021, from Indian Ocean Rim Association: https://www.iora.int/en/structuresmechanisms/mechanisms/working-group-on-heads-of-missionwghm

IORA. (n.d). Working Group on Trade and Investment (WGTI). Dikutip April 29, 2021, from Indian Ocean Rim Association: https://www.iora.int/en/structuresmechanisms/mechanisms/working-group-on-trade-investmentwgti

Jelita, I. N. (2020, Oktober 14). Kapal Vietnam Masih Marak Lakukan Illegal Fishing di Natuna. Dikutip April 25, 2021, from Media Indonesia: https://mediaindonesia.com/ekonomi/352669/kapalvietnam-masih-marak-lakukan-illegal-fishing-di-natuna 
Juliawati, T. M. (2018). Upaya Indonesia Dalam Mewujudkan Keamanan Maritim Pada Masa Pemerintahan Joko Widodo. Jurnal Ilmu Hubungan Internasional, 6(3), 1389-1404.

Keliat, M. (2009). Keamanan Maritim dan Implikasi Kebijakannya Bagi Indonesia. Jurnal Ilmu Sosial dan Ilmu Politik, 13(1), 111-129. doi: $10.22146 /$ jsp. 10970

Kemlu RI. (2019, April 8). Indian Ocean Rim Association. Dikutip April 29, 2021, from Kementerian Luar Negeri Republik Indonesia: https://kemlu.go.id/portal/id/read/167/halaman_list_lainnya/in dian-ocean-rim-association

KKP RI. (2019, April 11). KINERJA PENGAWASAN KKP SEPANJANG TRIWULAN 1/2019 TUNJUKKAN CAPAIAN POSITIF. Dikutip Januari 30 , 2021, from Direktorat Jenderal Pengawasan Sumber Daya Kelautan dan Perikanan: https: / kkp.go.id/djpsdkp/artikel/ 10030-kinerja-pengawasankkp-sepanjang-triwulan-1-2019-tunjukkan-capaian-positif

Leonard, A. E. (2019). The ASEAN Way to Asia-Pacific Security Community. Jurnal Sentris KSMPMI, 1, 22-31.

Lestari, D. I., Putra, A. R., \& Larasuci, A. Y. (2019). The main consequences of continued illegal, unreported, and unregulated (IUU) fishing within Indonesian waters for maritime security actors and coastal communities. Research Society and Development, 9(1).

Lisbet. (2016, Oktober). Indian Ocean Rim Association Concord dan Kepentingan Nasional Indonesia. Majalah Info Singkat Hubungan Internasional, 3(20).

Mière, C. L. (2014). Maritime Diplomacy in the 21st Century. New York: Routledge. 
Naidu, G. V. (2016). Indian Ocean Region: Need to Step-up Cooperation. In V. Sakhuja, \& K. Narula, Maritime Safety and Security in the Indian Ocean. New Delhi: Vij Books India.

OECD. (2004). Fish Piracy: Combating Illegal, Unreported, and Unregulated Fishing. Paris: OECD Publishing.

Permono, P. (2019). Abu Sayyaf Group in Southern Philippines After Bangsamoro Autonomous Region in Muslim Mindanao. Jurnal Studi Global Strategis, 13(2), 109-122.

Prasetyo, S. A. (2016). Indonesia's Chairmanship of IORA 2015-2017 and Beyond. Jurnal Kajian Wilayah, 7(1), 59-68. doi: $10.14203 / \mathrm{jkw} . v 7 \mathrm{i} 1.766$

Pratama, O. (2020, Juli 2020). Konservasi Perairan Sebagai Upaya menjaga Potensi Kelautan dan Perikanan Indonesia. Dikutip Januari 29, 2021, from Direktorat Jenderal Pengelolaan Ruang Laut KKP RI: https://kkp.go.id/djprl/artikel/21045-konservasiperairan-sebagai-upaya-menjaga-potensi-kelautan-dan-perikananindonesia\#: : text=Terbentang\%20dari\%20Sabang\%20hingga\%20M erauke,km2\%20adalah\%20Zona\%20Ekonomi\%20Eksklusif.

Putri, B. (2018). Indonesia's Role in the Indian Ocean Region Cooperation: Post-IORA Chairmanship Strategies. OISAA Journal of Indonesia Emas, 1(2), 110-124.

Rezasyah, T. (2017). Indian Ocean Rim Association (IORA) As Strategic Factor in Shaping Indonesia's Imagined Community As An Archipelagic Country. AEGIS: Journal of International Relations, 1(2), 210-216.

Ridho, M., \& Sudirman, A. (2020). Signifikansi Keamanan Maritim di ASEAN. Mandala: Jurnal Ilmu Hubungan Internasional, 165-182. doi:http://dx.doi.org/10.33822/3 
Septaria, E. (2016). IUU Fishing in Indonesia, Are ASEAN Member State Responsible For? International Journal of Marine and Coastal Law, $11(4)$.

Setiyanto, A. (2017). Strengthening Indonesia's Role In Indian Ocean Through IORA. Jurnal Pertahanan, 3(1), 15-32. doi:10.33172/jp.v3i1.156

Severino, R. C. (2006). Southeast Asia in Search of an ASEAN Community: Insights from the former ASEAN Secretary General. Singapore: Institute of Southeast Asian Studies.

Sheehan, J. J. (2006, February). The Problem of Sovereignty in European History. The American Historical Review, 111(1). doi:10.1086/ahr.111.1.1

Shie, T. R. (2004). Ports in a Storm? The Nexus between Counterterrorism, Counter proliferation, and Maritime Security in Southeast Asia. Issues and Insights, 4(4).

Singh, A. (2017). A Rule Based Maritime Order in the Indo-Pacific: Aligning the Building Blocks. Regional Outlook Paper, 57.

Suman, A., Irianto, H. E., Satria, F., \& Amri, K. (2016). POTENSI DAN TINGKAT PEMANFAATAN SUMBER DAYA IKAN DI WILAYAH PENGELOLAAN PERIKANAN NEGARA REPUBLIK INDONESIA (WPP NRI) TAHUN 2015 SERTA OPSI PENGELOLAANNYA. Jurnal Kebijakan Perikanan Indonesia, 8(2), 97-110. doi:http://dx.doi.org/10.15578/jkpi.8.2.2016.97-100

Susanti, A., Fahrudin, A., \& Kusumastanto, T. (2020). DAMPAK EKONOMI AKIBAT IUU FISHING PERIKANAN TANGKAP PELAGIS BESAR DI WPPNRI 715. Jurnal Sosial Ekonomi KP, 15(2), 135-144. doi:http://dx.doi.org/10.15578/jsekp.v15i2.8178 
Taufika, R. (2020). Latent Securitisation of Illegal, Unreported, and Unregulated (IUU) Fishing in Indonesia. Global: Jurnal Politik Internasional, 22(1), 26-53. doi:10.7454/global.v22i1.488

Waluyo, B. (2020). China dan Vietnam: Ketiadaan Konflik Terbuka di Laut Cina Selatan. Jurnal Dinamika Global. 5(2).

Wee, J. Y. (2008). Maritime Terrorism Threat in Southeast Asia and Its Challenges. Journal of the Singapore Armed Forces, 43(2), 32-44. 319-333

Wicaksana, S. W. (2017). Nilai Strategis Indian Ocean Rim Association Bagi Indonesia Dalam Penerapan Poros Maritim Dunia Tahun 2015. Jurnal Online Mahasiswa FISIP, 4(1), 1-10. 